\title{
Exploring DNA methylation changes in promoter, intragenic, and intergenic regions as early and late events in breast cancer formation
}

Garth H. Rauscher ${ }^{1 *}$, Jacob K. Kresovich ${ }^{1}$, Matthew Poulin ${ }^{2}$, Liying Yan², Virgilia Macias ${ }^{3}$, Abeer M. Mahmoud ${ }^{3}$, Umaima Al-Alem ${ }^{1}$, Andre Kajdacsy-Balla ${ }^{3}$, Elizabeth L. Wiley ${ }^{3}$, Debra Tonetti ${ }^{4}$ and Melanie Ehrlich ${ }^{5^{*}}$

\begin{abstract}
Background: Breast cancer formation is associated with frequent changes in DNA methylation but the extent of very early alterations in DNA methylation and the biological significance of cancer-associated epigenetic changes need further elucidation.

Methods: Pyrosequencing was done on bisulfite-treated DNA from formalin-fixed, paraffin-embedded sections containing invasive tumor and paired samples of histologically normal tissue adjacent to the cancers as well as control reduction mammoplasty samples from unaffected women. The DNA regions studied were promoters (BRCA1, CD44, ESR1, GSTM2, GSTP1, MAGEA1, MSI1, NFE2L3, RASSF1A, RUNX3, SIX3 and TFF1), far-upstream regions (EN1, PAX3, PITX2, and SGK1), introns (APC, EGFR, LHX2, RFX1 and SOX9) and the LINE-1 and satellite 2 DNA repeats. These choices were based upon previous literature or publicly available DNA methylome profiles. The percent methylation was averaged across neighboring CpG sites.

Results: Most of the assayed gene regions displayed hypermethylation in cancer vs. adjacent tissue but the TFF1 and MAGEA1 regions were significantly hypomethylated ( $p \leq 0.001$ ). Importantly, six of the 16 regions examined in a large collection of patients (105 - 129) and in 15-18 reduction mammoplasty samples were already aberrantly methylated in adjacent, histologically normal tissue vs. non-cancerous mammoplasty samples ( $p \leq 0.01)$. In addition, examination of transcriptome and DNA methylation databases indicated that methylation at three non-promoter regions (far-upstream EN1 and PITX2 and intronic LHX2) was associated with higher gene expression, unlike the inverse associations between cancer DNA hypermethylation and cancer-altered gene expression usually reported. These three non-promoter regions also exhibited normal tissue-specific hypermethylation positively associated with differentiation-related gene expression (in muscle progenitor cells vs. many other types of normal cells). The importance of considering the exact DNA region analyzed and the gene structure was further illustrated by bioinformatic analysis of an alternative promoter/intron gene region for $A P C$.
\end{abstract}

Conclusions: We confirmed the frequent DNA methylation changes in invasive breast cancer at a variety of genome locations and found evidence for an extensive field effect in breast cancer. In addition, we illustrate the power of combining publicly available whole-genome databases with a candidate gene approach to study cancer epigenetics.

Keywords: Breast cancer, DNA methylation, Hypomethylation, Hypermethylation, Pyrosequencing, Tumor suppressor genes, Field effect, TCGA database, Transcriptome, Histone modifications

\footnotetext{
* Correspondence: garthr@uic.edu; ehrlich@tulane.edu

'Division of Epidemiology and Biostatistics, University of Illinois-Chicago,

School of Public Health, M/C 923, Chicago, IL 60612, USA

${ }^{5}$ Human Genetics Program, Tulane Cancer Center, and Center for

Bioinformatics and Genomics, Tulane University Health Sciences Center, 1430

Tulane Ave., New Orleans, LA 70112, USA

Full list of author information is available at the end of the article
}

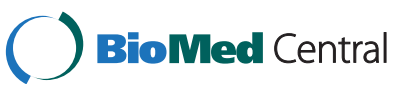

(c) 2015 Rauscher et al. Open Access This article is distributed under the terms of the Creative Commons Attribution 4.0 International License (http://creativecommons.org/licenses/by/4.0/), which permits unrestricted use, distribution, and reproduction in any medium, provided you give appropriate credit to the original author(s) and the source, provide a link to the Creative Commons license, and indicate if changes were made. The Creative Commons Public Domain Dedication waiver (http://creativecommons.org/publicdomain/zero/1.0/) applies to the data made available in this article, unless otherwise stated. 


\section{Background}

Aberrant DNA methylation is a hallmark of cancer [1] and may function in various ways to influence transcription, as is the case in normal differentiation [2]. Comparisons of DNA methylation in cancers to methylation in an analogous normal tissue or to methylation in a variety of normal tissues revealed that cancer is very often associated with a global reduction in DNA methylation [3-5]. Hypermethylation of promoter regions overlapping CpG islands (CpG-rich DNA sequences), most notably in some tumor suppressor genes, is also a nearly universal feature of human cancer [6-9].

Because the terms 'hypermethylation' and 'hypomethylation' indicate changes relative to some appropriate standard [10], the choice of normal tissue for comparison is critical. In cancer patients, otherwise normal-appearing tissue that is adjacent to the tumor is often used as the normal control. However, such tissue can contain early changes in DNA methylation that may contribute to tumor initiation or may just be markers of the onset of neoplasia $[11,12]$. In the present study, we address the question of the prevalence of early DNA methylation changes and field effects (genetic or epigenetic abnormalities in tissues that appear histologically normal) in breast cancer development using paired adjacent normal and invasive tissue from a total of 129 patients with breast cancer together with 18 reduction mammoplasty controls from cancer-free women. The DNA regions examined for differential methylation included promoters, far-upstream regions, and introns as well as DNA repeats. The geneassociated regions included tumor suppressor genes, stem cell-associated genes and transcription factor genes. The regions for analysis were chosen using findings from the literature and bioinformatics, especially epigenetic data from the Encyclopedia of DNA Elements (ENCODE) at the UCSC Genome Browser [13]. We also used bioinformatics to compare our DNA methylation results with those in The Cancer Genome Atlas (TCGA) [14], one of the most comprehensive public databases on DNA methylation changes in breast cancer. To elucidate the biological significance of our findings, we examined whole-genome expression data for breast cancers from TCGA as well as DNA epigenetic, chromatin epigenetic and transcriptome profiles from cell cultures represented at the UCSC Genome Browser [13, 15]. Our results provide evidence for frequent field effects in breast cancer development and illustrate the power of combining whole-genome epigenome and transcriptome profiles with examination of individual gene regions.

\section{Methods}

\section{Source of samples}

Breast cancer patients $(\mathrm{N}=129)$ came from the Breast Cancer Care in Chicago (BCCC) study and were diagnosed at one of many Chicago area hospitals. The study was approved by the University of Illinois at Chicago institutional review board. Women were between the ages of 30 and 79, self-identified as non-Hispanic White, non-Hispanic Black or Hispanic, resided in Chicago, had a first primary in situ or invasive breast cancer diagnosed between 2005 and 2008 and gave written consent to participate in the study and to allow the research staff to obtain samples of their breast tumors from diagnosing hospitals. In addition, 18 unaffected, cancer-free patients who underwent a reduction mammoplasty between 2005-2008 served as non-cancerous controls. The 18 control tissues were made available through a standardized protocol involving an honest broker within the UIC department of pathology. For all patients, hematoxylin and eosin (H\&E) stained slides from formalin-fixed, paraffin-embedded (FFPE) tumor blocks were examined to determine representative areas of invasive tumor, histologically and morphologically normal-appearing breast tissue adjacent to the tumor, or confirmed histologically normal tissue obtained from reduction mammoplasty samples (referred to as control or 'non-cancerous' samples). For lumpectomies, adjacent breast tissue was usually chosen from the same block as the tumor. However, when available, a separate block containing breast tissue and no tumor was used as the non-malignant, adjacent sample. Tissue core samples were precisely cut from the selected area using a semiautomated tissue arrayer (Beecher Instruments, Inc.). Because the tissue was fixed and sealed by paraffin, cells from the invasive tissue could not become dislodged and contaminate the adjacent tissue or vice versa.

\section{DNA methylation analysis}

Dissolution of paraffin was accomplished by the addition of $1 \mathrm{~mL}$ of clearing agent (Histochoice) and incubation at $65{ }^{\circ} \mathrm{C}$ for $30 \mathrm{~min}$. Samples were digested by the addition of $100 \mu \mathrm{L}$ of digestion buffer consisting of $10 \mu \mathrm{L}$ 10X Target Retrieval Solution high $\mathrm{pH}$ (DAKO, Glostrup, Denmark), $75 \mu \mathrm{L}$ of ATL Buffer (Qiagen), and $15 \mu \mathrm{L}$ of proteinase $\mathrm{K}$ (Qiagen) and incubation at $65{ }^{\circ} \mathrm{C}$ overnight. They were then vortexed and checked for complete digestion. The sample volume was brought up to $\sim 100 \mu \mathrm{L}$, and $20 \mu \mathrm{L}$ of each sample was treated with bisulfite and purified using the Zymo EZ-96 DNA Methylation-Direct ${ }^{\mathrm{TM}} \mathrm{Kit}$, with a 15-min denaturation step at $98{ }^{\circ} \mathrm{C}$ followed by a 3.5 -h conversion at $64{ }^{\circ} \mathrm{C}$, an additional 15 -min denaturation at $98{ }^{\circ} \mathrm{C}$ and a 60-min incubation at $64{ }^{\circ} \mathrm{C}$. DNA was eluted in $40 \mu \mathrm{L}$ of elution buffer. Then, PCR was performed with $0.2 \mu \mathrm{M}$ of each primer, one of which was biotinylated, and the final PCR product was purified (Streptavidin Sepharose HP, Amersham Biosciences, Uppsala, Sweden), washed, alkaline-denatured, and rewashed (Pyrosequencing Vacuum Prep Tool, Qiagen). Then, pyrosequencing primer $(0.5 \mu \mathrm{M})$ was annealed to the 
purified single-stranded PCR product, and $10 \mu \mathrm{L}$ of the PCR products were sequenced by Pyrosequencing PSQ96 HS System (Biotage AB) following the manufacturer's instructions. The amplicon regions used are given in Table 1 . The methylation status of each locus was analyzed individually as a T/C SNP using Pyromark Q96 software (Qiagen, Germantown, Maryland).

\section{Quality control of DNA methylation analysis}

All primer-pairs passed tests for sensitivity, reproducibility, and lack of amplification bias (EpigenDx, Hopkinton, MA). All reactions had negligible levels of persisting non-CpG cytosine residues. For each set of PCR primers, a dilution series of technical triplicates was examined with $\leq 15 \mathrm{ng}$ bisulfite-treated DNA. Primer-pairs were discarded if the signal for a single nucleotide peak was below 50 relative light units (RLU's). The signal to noise $(\mathrm{S} / \mathrm{N})$ ratio was calculated by dividing the RLU signal from a single nucleotide incorporation by the RLU value from a negative control nucleotide incorporation, and primer-pairs were discarded if the $\mathrm{S} / \mathrm{N}$ ratio was less than 10 . The reproducibility of percent methylation was also assessed and primer-pairs were excluded if the coefficient of variation exceeded $5 \%$. The lack of amplification bias was demonstrated for each

Table 1 List of studied gene regions and number of CpGs covered, Breast Cancer Care in Chicago study (2005-2008)

\begin{tabular}{|c|c|c|c|c|c|c|}
\hline Gene/RNA isoform ${ }^{a}$ & Test region & Test region coordinates (hg19) & Distance from TSS $(b p)^{b}$ & $\mathrm{CGl}^{\mathrm{C}}$ & $\# C p G s^{d}$ & $\mathrm{TSG}^{\mathrm{e}}$ \\
\hline \multicolumn{7}{|l|}{ Promoter region } \\
\hline BRCA1 & Exon 1 (extended promoter) & chr17: 41277463-41277365 & +37 to +135 & No & 11 & Yes \\
\hline CD44 & Promoter & chr1 1: 35160374-35160443 & -43 to +26 & Yes & 8 & No \\
\hline ESR1 & Exon 2 (extended promoter) & chr6: 152129110 - 152129167 & +656 to +713 & Yes & 5 & Unclear \\
\hline GSTM2 & Promoter & chr1: 110210582-110210641 & -62 to -3 & Yes & 8 & No \\
\hline GSTP1 & Exon 1 (extended promoter) & chr11: $67351205-67351215$ & +139 to +149 & Yes & 4 & Yes \\
\hline MAGEA $1^{f}$ & Promoter & chrX: 152486180-152486129 & -13 to -64 & No & 6 & No \\
\hline MSI1 & Promoter & chr12: 120807571-120807474 & -588 to -491 & No & 5 & \\
\hline NFE2L3 & Exon 1 (Extended promoter) & chr7: 26192663-26192744 & +816 to +897 & Yes & 14 & No \\
\hline RASSF1A & Exon 1 (extended promoter) & chr3: 50378293-50378233 & +74 to +134 & Yes & 9 & Yes \\
\hline RUNX3 & Exon 1 (extended promoter) & chr1: 25256198-25256306 & +464 to +572 & Yes & 28 & Yes \\
\hline $\mathrm{SIX} 3$ & Exon 1 (extended promoter) & chr2: 45169609-45169529 & +492 to +572 & Yes & 12 & Unclear \\
\hline TFF1 & Promoter & chr21: 43786664-43786628 & -20 to +16 & No & 5 & Unclear \\
\hline \multicolumn{7}{|c|}{ Upstream of promoter } \\
\hline EN1 & Upstream of promoter & chr2: 119611385-119611338 & -5579 to -5626 & Yes & 6 & No \\
\hline $\operatorname{PAX} 3^{9}$ & Far upstream & chr2: 223170608-223170643 & -6928 to -6893 & Yes & 5 & No \\
\hline PITX2 $2^{f, h}$ & Far upstream or intron I & chr4: 111562566-111562677 & -18312 to $-18413 /+602$ to +713 & No & 10 & No \\
\hline $\mathrm{SGK} 1^{\mathrm{h}}$ & Far upstream/ alt. exon 1 & chr6: 134638893-134638831 & -14823 to $-14761 /+303$ to +365 & Yes & 6 & Unclear \\
\hline \multicolumn{7}{|l|}{ Introns } \\
\hline APC & Intron 1 or promoter & chr5: 112073426-112073445 & +30224 to $+30243 /-130$ to -111 & No & 4 & Yes \\
\hline EGFR & intron 1 & chr7: 55088080-55088104 & +1355 to +1379 & Yes & 4 & No \\
\hline LHX2 & Intron 3 & chr9: 126777854-126777983 & +3966 to +4095 & Yes & 11 & No \\
\hline $\operatorname{RFX} 1^{f}$ & Intron 7 & chr19: 14089984-14089969 & +27150 to +27165 & No & 4 & No \\
\hline sox9 & Intron 2 & chr17: 70119151-70119195 & +1990 to +2034 & Yes & 4 & No \\
\hline \multicolumn{7}{|l|}{ DNA Repeats } \\
\hline LINE-1 & N.A. & DNA Repeat & N.A. & & 4 & N.A. \\
\hline Sat2 & N.A. & DNA Repeat & N.A. & & 2 & N.A. \\
\hline
\end{tabular}

${ }^{a}$ Where there are multiple RefSeq RNA isoforms and expression in HMEC cells by RNA-seq (ENCODE/Cold Spring Harbor), the RNA isoform closest to the predominant HMEC RNA was used in this table to determine the TSS. The isoforms for calculation of the distance from the TSS are given in Additional file 1: Tables S1 and S2

${ }^{\mathrm{b}} \mathrm{TSS}$, transcription start site for the indicated RefSeq isoform. N.A., not applicable

${ }^{\mathrm{C}} \mathrm{CGI}, \mathrm{CpG}$ island overlapping the test region

${ }^{\mathrm{d}}$ The number of $\mathrm{CpG}$ dinucleotide pairs in the test region (the amplicon used for pyrosequencing minus the primer regions)

eTSG, Tumor suppressor gene

${ }^{f}$ Although the sequences were in regions that did not make the criteria to be classified as CGI [13], the regions were rich in CpG compared to the average for human DNA

${ }^{9}$ There is a little expressed, primate specific gene, $C C D C 140$, between $P A X 3$ and the test region whose $5^{\prime}$ end overlaps the $5^{\prime}$ end of $P A X 3$

hThere are distant alternative 5 ' ends of these genes 
utilized primer-pair by mixing different relative amounts of human placental DNA (Bioline, Taunton, MA) that had been methylated (with SssI-methyltransferase) and amplified DNA left unmethylated (HGHM5 and HGUM5, EpigenDx). The empirically determined methylation values were compared with the known values. An R-square value of $>0.9$ was required for validation.

\section{Statistical analysis \\ Breast Cancer Care in Chicago pyrosequencing study}

We conducted pyrosequencing methylation assays on 276 FFPE samples including 258 samples of paired invasive and adjacent tissue from 129 patients with invasive breast cancer, as well as 18 reduction mammoplasty noncancerous controls. Methylation values were averaged across multiple neighboring CpG sites to create a single value for percent methylation for each assay. Mean and $95 \%$ confidence intervals for percent methylation were estimated for each gene separately for control mammoplasty, adjacent and cancer samples. Differences in means between unpaired control mammoplasty vs. adjacent and cancer tissues were evaluated via p-values from independent Wilcoxin rank-sum tests, whereas differences in means between paired adjacent and cancer tissues were evaluated via $\mathrm{p}$-values from dependent Wilcoxon signedrank tests. Differences in means between adjacent and cancer tissues were also estimated in linear regression with generalized estimating equations to account for the paired nature of the samples, and $95 \%$ confidence intervals were estimated via 1000 bootstrap replications with bias correction. These models were adjusted for patient age, race/ethnicity and tumor characteristics (stage at diagnosis, tumor grade and either adjusted for or stratified by ER/PR status). For differential methylation in cancer vs. adjacent tissue at DNA regions in the complete sample set, we used a significance level of $p \leq 0.001$. For those DNA regions not pursued beyond the pilot phase, which were examined in only 37 pairs of cancer and adjacent tissue, we used a significance level of $\mathrm{p} \leq 0.01$.

\section{The Cancer Genome Atlas (TCGA) bioinformatics study}

We examined methylation results for 192 samples of paired breast cancers and normal tissue $(\mathrm{N}=96)$, based on TCGA profiles [14] from the Infinium HumanMethylation450 array performed on frozen (not formalin fixed) samples. Differences in mean methylation between paired normal and invasive tissues were evaluated using p-values from dependent Wilcoxon signed-rank tests.

Additionally, to examine the correlation between regional methylation and gene expression values, invasive breast cancer tumors with both methylation results and gene expression results $(\mathrm{N}=800)$ were obtained from TCGA bioportal $[16,17]$. Methylation value data were aquired using the Infinium HumanMethylation450 assay and gene expression data were taken as z-scores using Illumina HighSeq 2000 Total RNA Sequencing Version 2. Spearman correlation coefficients were calculated to measure the association between regional loci methylation level and gene expression level. The level for significance for both of the previously identified analyses was defined as $\mathrm{p} \leq 0.01$. Lastly, other wholegenome databases that are part of the ENCODE project $[18,19]$ and publicly available profiles for all mappable CpGs in control and cancer-derived breast epithelial cell cultures using next-generation sequencing of bisulfitetreated DNA (bisulfite-seq) [15] were examined for DNA methylation, transcription, or histone modification as described in Results.

\section{Results}

\section{Choice of regions for analysis}

We chose a diverse set of genes and two DNA repeats (Table 1) to assay for DNA methylation in cancer, adjacent and control mammoplasty tissues. Eight of the 23 examined DNA regions overlapped or were near regions previously reported to be hypermethylated in breast cancer vs. non-cancerous breast tissue, namely, EGFR [20], GSTP1 [21], LHX2 [22], PITX2 [23], RASSF1A [24], RUNX3 [25], APC [26] and BRCA1 [27, 28] or hypomethylated in breast cancer vs. normal breast, namely, TFF1 [29], satellite 2 and LINE-1, DNA repeats [30, 31]. In addition, the first six of the above-mentioned gene regions displayed hypermethylation in one or two breast cancer cell lines (MCF-7 and T-47D) relative to a human breast epithelial cell culture derived from normal breast tissue (human mammary epithelial cells, HMEC) and compared with most normal tissues, including breast tissue as seen in whole-genome DNA methylation data (reduced representation bisulfite sequencing, RRBS) from the ENCODE project [5, 13, 19]. An additional seven gene regions (EN1, PAX3, SIX3, SOX9, RFX1, $S G K 1$ and NFE2L3) were chosen mostly on the basis of hypermethylation profiled by RRBS in breast cancer cells lines (and often other cancer cell lines) vs. the abovementioned normal cell cultures or tissues [13]. The first five of these genes also had been previously reported to display hypermethylation in non-breast neoplasms vs. control tissue [32-35].

Figure 1 illustrates ENCODE data at the UCSC Genome Browser [13] for the studied region far upstream of $E N 1$, one of the gene regions chosen for examination in this study on the basis of RRBS DNA methylation data for breast cancer cell lines vs. control cells and tissues. EN1 encodes a homeobox-containing transcription factor that is implicated in the development of the nervous system and serves as a marker of certain neurons [36]. Underneath the diagrammed gene structure (Panel a) are the aligned $\mathrm{CpG}$ islands in the illustrated region 


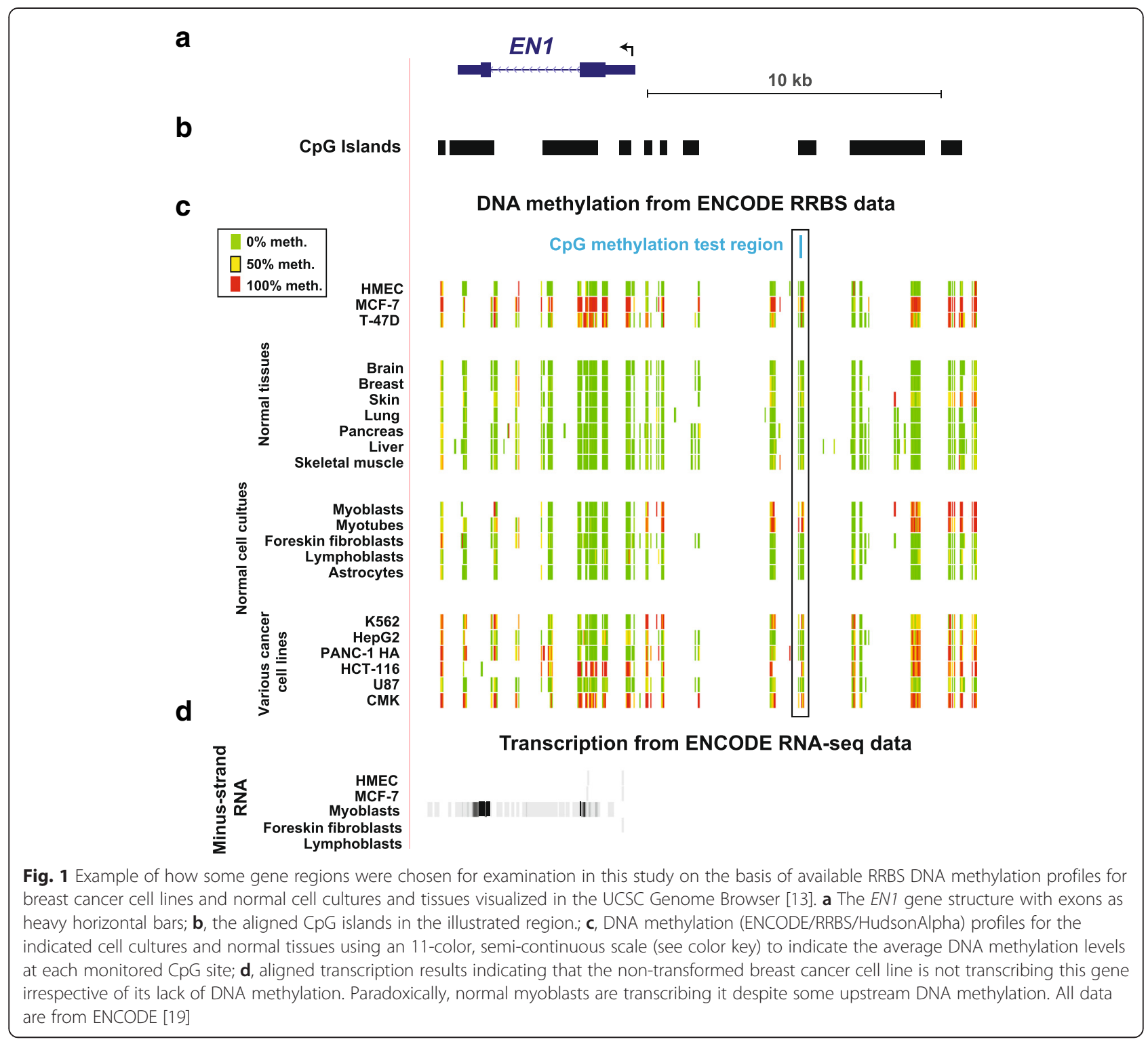

(Panel b). The tracks in Panel c show the DNA methylation status quantified at the RRBS-detected CpGs in a variety of cell cultures and normal tissues using an 11color, semi-continuous scale (see color key) to indicate the average DNA methylation levels at each monitored CpG site (ENCODE/RRBS/HudsonAlpha Institute, [13]). The MCF-7 breast cancer cell line and several diverse cancer cell lines were hypermethylated throughout most of the gene and its upstream region relative to HMEC, normal breast tissue, other normal tissues and the majority of non-cancer cell cultures (Panel $\mathrm{c}$ and data not shown from ENCODE [13]). The exceptions were normal muscle cell cultures (myoblasts and myotubes) but these were methylated in a smaller region that did not overlap the beginning of the gene as did the hypermethylation in MCF-7 cells. T-47D, the second examined breast cancer cell line in this RRBS database, was hypermethylated relative to HMEC but to a lesser extent than for MCF-7 cells.

We also examined two gene regions (ESR1 and GSTM2) found to display hypermethylation preferentially in more aggressive breast cancers [37, 38]. In addition, we studied CD44 and MSI1, which have been reported to have promoter hypomethylation in triplenegative breast cancers, that is, cancers that lack estrogen receptors (ER), progesterone receptors (PR), and human epidermal growth factor-2 receptors (HER2) [39]. The last gene region we examined was MAGEA1, which encodes a cancer-testis antigen that is not expressed in normal somatic tissues but is sometimes expressed in breast cancer [40]. Cancer-testis antigen genes are often hypomethylated in various kinds of 
cancer [41], although the methylation status of MAGEA1 in breast cancer was not known.

\section{Samples and method used for DNA methylation analysis} The breast tissue samples analyzed for DNA methylation were invasive cancer (referred to as "cancer"), histologically normal tissue adjacent to the cancer (referred to as "adjacent tissue") and non-cancerous reduction mammoplasty samples (referred to as "control mammoplasty"). Characteristics of the 129 breast cancer patients and their tumors are listed in Table 2. The carcinomas were equally likely to be stage I vs. later stages, equally distributed across histological grades, and one third of them lacked both estrogen and progesterone receptors. Before studying the full sample set, we conducted a pilot study on the 23 test regions using paired samples of cancer and adjacent tissue from 37 patients, and on samples from 18 reduction mammoplasty patients. Of the 23 test regions, 16 were analyzed in an additional set of 92 patients with paired cancer and adjacent tissue samples to give a total of 276 samples.

Methylation analysis was performed by pyrosequencing of bisulfite-treated DNA. This method allowed us to monitor individual reactions for incomplete bisulfite modification and to check for PCR-bias [42, 43]. We used FFPE-derived DNA, which is partly degraded and difficult to analyze because of crosslinking resulting from

Table 2 Characteristics of the 129 breast cancer patients with adjacent normal and/or invasive samples, Breast Cancer Care in Chicago study (2005-2008)

\begin{tabular}{lll}
\hline Patient characteristic & No. & Percent \\
\hline Age & 44 & 34 \\
$<50$ & 36 & 28 \\
$50-59$ & 32 & 25 \\
$60-69$ & 17 & 13 \\
$70-79$ & & \\
Race/Ethnicity & 42 & 33 \\
non-Hispanic White & 57 & 44 \\
non-Hispanic Black & 30 & 23 \\
Hispanic & & \\
Stage at Diagnosis & 60 & 47 \\
Stage I & 68 & 53 \\
Stage II-IV & & 32 \\
Histologic Grade & 39 & 34 \\
Low & 42 & 34 \\
Intermediate & 42 & 67 \\
High & & 33 \\
ER/PR status & 40 & \\
One or both positive & & \\
Double negative & & \\
\hline
\end{tabular}

the formalin fixation process [44], and which may be available in only small amounts. These problems are compounded by further degradation associated with bisulfite treatment for the methylation analysis. Bisulfitebased pyrosequencing overcomes these problems and provides accurate quantification [43].

\section{Variation in DNA methylation among samples of the same tissue type}

As expected for cancer-linked DNA methylation changes [7], there was large variability in the average 5methylcytosine $(5 \mathrm{mC})$ content at a given test region among individual cancer samples, as seen in the high standard deviation (SD) relative to the mean methylation values (Table 3). The between-sample variability contrasted with the much lower within-sample variability of technical duplicates (data not shown), observed in the pilot study. Moreover, the control mammoplasty samples generally showed less variability in average $5 \mathrm{mC}$ content compared with adjacent or cancer samples (Table 3).

\section{DNA hypermethylation in cancer vs. adjacent and control mammoplasty samples}

Figure 2 (Panel a) displays the mean percent methylation and $95 \%$ confidence limits for each of the 23 studied DNA regions and shows the results separately for control mammoplasty, adjacent and cancer samples. Hypermethylation in cancer vs. adjacent samples was seen at a significance level of $\mathrm{p} \leq 0.001$ for 12 of the 16 test regions in the large-scale study and at a significance level of $\mathrm{p} \leq 0.01$ for three of the seven regions not pursued beyond the pilot phase (Table 3 ). Twelve of the regions were also significantly hypermethylated in cancer vs. control mammoplasty samples $(\mathrm{p} \leq 0.01)$ (Table 3$)$. The difference in the average percent methylation for significiantly hypermethylated sequences in cancer vs. adjacent tissue or for cancer vs. control mammoplasty tissue was largest for RASSF1A (23.6 and 30.5, respectively). Cancer-associated hypermethylation was seen in test sequences that were in extended promoter regions (regions immediately upstream or downstream of the transcription start site, TSS), in sequences upstream of promoter regions and in introns. A mostly similar pattern of cancer hypermethylation of these gene regions was observed in TCGA for breast cancer and paired normal samples (Fig. 2, panel b).

Eight of the ten test regions overlapping DNA sequences previously reported to be hypermethylated in breast cancer vs. nonmalignant breast tissue or in more aggressive vs. less aggressive cancer types (APC, EGFR, GSTM2, GSTP1, LHX2, PITX2, RASSF1A and RUNX3) exhibited hypermethylation in this study at the designated $\mathrm{p}$-value cutoff levels $(\mathrm{p}<0.001$ and $\mathrm{p}<0.01$, 
Table 3 Mean percent methylation by gene and tissue type from the Breast Cancer Care in Chicago study

\begin{tabular}{|c|c|c|c|c|c|c|c|c|c|c|c|c|c|c|c|}
\hline \multirow[t]{2}{*}{ DNA region } & \multicolumn{3}{|c|}{ Control $^{a}$} & \multicolumn{3}{|c|}{ Adjacent $^{\mathrm{b}}$} & \multicolumn{3}{|c|}{ Invasive $^{c}$} & \multicolumn{2}{|c|}{ Adjacent vs. control } & \multicolumn{2}{|c|}{ Invasive vs. control } & \multicolumn{2}{|c|}{ Invasive vs. adjacen } \\
\hline & $\bar{N}$ & Mean & SD & $\bar{N}$ & Mean & SD & $\bar{N}$ & Mean & SD & $\overline{\text { Diff. }}$ & $P$-value ${ }^{d}$ & $\overline{\text { Diff. }}$ & $P$-value ${ }^{d}$ & $\overline{\text { Diff. }}$ & $P$-value ${ }^{e}$ \\
\hline \multicolumn{16}{|c|}{ Promoter region } \\
\hline BRCA1 & 15 & 1.6 & 1.1 & 105 & 1.4 & 4.3 & 105 & 3.0 & 9.6 & -0.2 & NS & 1.4 & NS & 1.6 & 0.031 \\
\hline $\mathrm{CD} 44^{f}$ & 18 & 1.6 & 0.6 & 37 & 1.8 & 0.9 & 37 & 2.6 & 2.7 & 0.2 & NS & 1.0 & NS & 0.8 & NS \\
\hline$E S R 1^{f}$ & 18 & 5.9 & 3.1 & 37 & 7.9 & 6.0 & 37 & 6.7 & 7.8 & 2.0 & NS & 0.8 & NS & -1.2 & NS \\
\hline GSTM2 & 16 & 1.8 & 2.0 & 107 & 3.0 & 6.1 & 107 & 19.3 & 22.9 & 1.2 & NS & 17.5 & 0.004 & 16.3 & $<0.0001$ \\
\hline GSTP1 & 17 & 2.5 & 2.0 & 118 & 1.6 & 3.7 & 118 & 9.9 & 16.8 & -0.9 & NS & 7.4 & NS & 8.3 & $<0.0001$ \\
\hline$M A G E A 1^{f}$ & 17 & 84.8 & 4.9 & 32 & 84.2 & 4.8 & 37 & 67.0 & 16.2 & -0.6 & NS & -17.8 & 0.0001 & -17.2 & $<0.0001$ \\
\hline $\mathrm{MSI}^{f}$ & 18 & 3.8 & 2.1 & 36 & 4.2 & 2.5 & 37 & 9.2 & 7.4 & 0.4 & NS & 5.3 & 0.0001 & 5.0 & 0.0003 \\
\hline NFE2 $L 3^{f}$ & 17 & 28.9 & 14.7 & 36 & 26.9 & 13.7 & 37 & 33.7 & 24.4 & -2.0 & NS & 4.8 & NS & 6.8 & NS \\
\hline RASSF1A & 18 & 2.8 & 2.2 & 124 & 9.7 & 10.7 & 124 & 33.3 & 23.4 & 6.9 & $<0.0001$ & 30.5 & $<0.0001$ & 23.6 & $<0.0001$ \\
\hline RUNX3 & 17 & 3.3 & 1.2 & 119 & 4.0 & 3.3 & 119 & 11.4 & 12.7 & 0.7 & NS & 8.1 & 0.061 & 7.4 & $<0.0001$ \\
\hline SIX3 & 17 & 5.8 & 2.8 & 115 & 5.3 & 4.0 & 115 & 15.7 & 14.9 & -0.5 & NS & 9.9 & 0.026 & 10.4 & $<0.0001$ \\
\hline TFF1 & 18 & 81.8 & 5.4 & 122 & 72.0 & 16.9 & 122 & 49.2 & 22.3 & -9.8 & 0.008 & -32.6 & $<0.0001$ & -22.8 & $<0.0001$ \\
\hline \multicolumn{16}{|c|}{ Upstream of promoter } \\
\hline EN1 & 18 & 17.8 & 5.3 & 122 & 20.0 & 10.2 & 122 & 32.9 & 15.3 & 2.2 & NS & 15.1 & $<0.0001$ & 12.9 & $<0.0001$ \\
\hline PAX3 & 17 & 2.9 & 1.2 & 121 & 4.0 & 5.2 & 121 & 10.8 & 11.1 & 1.1 & NS & 7.9 & 0.0003 & 6.8 & $<0.0001$ \\
\hline PITX $2^{f}$ & 17 & 26.5 & 6.1 & 35 & 27.6 & 8.6 & 36 & 36.1 & 11.3 & 1.1 & NS & 9.6 & 0.001 & 8.5 & $<0.0001$ \\
\hline SGK1 & 18 & 1.6 & 1.2 & 124 & 3.9 & 3.7 & 124 & 13.0 & 12.2 & 2.3 & $<0.0001$ & 11.4 & $<0.0001$ & 9.1 & $<0.0001$ \\
\hline \multicolumn{16}{|l|}{ Introns } \\
\hline $\mathrm{APC}$ & 18 & 2.0 & 1.9 & 114 & 2.9 & 8.3 & 114 & 14.8 & 19.6 & 0.9 & NS & 12.8 & 0.058 & 11.9 & $<0.0001$ \\
\hline EGFR & 18 & 4.5 & 1.3 & 126 & 7.3 & 5.2 & 126 & 19.4 & 14.8 & 2.8 & 0.006 & 14.9 & $<0.0001$ & 12.1 & $<0.0001$ \\
\hline $\operatorname{LHX2^{f}}$ & 18 & 21.1 & 5.3 & 36 & 25.8 & 13.1 & 37 & 36.1 & 12.6 & 4.7 & NS & 15.0 & $<0.0001$ & 10.3 & 0.0007 \\
\hline RFX1 & 18 & 18.0 & 5.3 & 126 & 19.3 & 9.7 & 126 & 39.4 & 13.1 & 1.3 & NS & 21.4 & $<0.0001$ & 20.1 & $<0.0001$ \\
\hline SOX9 & 18 & 8.4 & 4.3 & 123 & 9.1 & 7.4 & 123 & 15.2 & 14.3 & 0.7 & NS & 6.8 & NS & 6.1 & 0.002 \\
\hline \multicolumn{16}{|l|}{ DNA Repeats } \\
\hline LINE-1 & 18 & 68.7 & 1.4 & 129 & 72.8 & 2.6 & 129 & 71.2 & 4.3 & 4.1 & $<0.0001$ & 2.5 & 0.0003 & -1.6 & 0.001 \\
\hline Sat2 & 18 & 52.6 & 8.0 & 128 & 57.4 & 12.7 & 128 & 52.0 & 13.4 & 4.8 & 0.002 & -0.6 & NS & -5.4 & $<0.0001$ \\
\hline
\end{tabular}

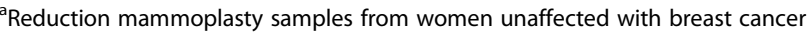

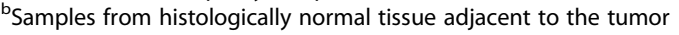

'Samples from the cancer component of the tumor

${ }^{d}$ From an independent sample Wilcoxon Rank Sum test comparing control mammoplasty vs. adjacent samples

${ }^{\mathrm{e}}$ From a dependent sample Wilcoxon Sign Rank test. P-values $>0.10$ are suppressed. Diff, difference in mean methylation; SD, standard deviation

${ }^{f}$ These seven assays were not pursued beyond the pilot phase and, therefore, had 32-37 paired cancer and adjacent samples instead of 105-129

Differences were determined to be statistically significant at $p<0.001$ for the complete sample set and $p<0.01$ for regions only examined in the pilot study

Table 3). Two other genes (BRCA1 and ESR1) displayed very small changes in the extent of methylation $(<2 \%$ differential for cancer vs. adjacent tissue). BRCA1 methylation was low for all three tissue types, ranging from a mean of $1 \%$ in adjacent to only $3 \%$ in cancer samples. However, BRCA1 showed the largest relative SD of all tested regions ( $>3$-fold, Table 3). Four percent of cancer samples and none of the adjacent or control mammoplasty samples displayed $B R C A 1$ methylation in excess of $20 \%$ (results not shown). For additional DNA regions that were hypermethylated in breast cancer cell lines or in cancers other than breast (EN1, NFE2L3, PAX3, RFX1, SGK1,
SIX3 and SOX9), significant hypermethylation was seen in the cancer tissue compared with adjacent tissue with the exceptions of SOX9 $(\mathrm{p}=0.002)$ and NFE2L3 (Table 3).

Results were not substantively different after adjusting for patient and tumor characteristics (age, race/ethnicity, ER/PR status, stage and grade) (Table 4). When stratifying estimates by ER/PR status, several genes appeared to display differential changes in methylation for adjacent vs. cancer tissues (Table 4). GSTM2 exhibited more hypermethylation for ER/PR negative tumors $(\mathrm{p}<0.05)$, whereas EGFR displayed greater hypermethylation for ER/PR positive tumors $(\mathrm{p}<0.05)$. TFF1 and MAGEA1 

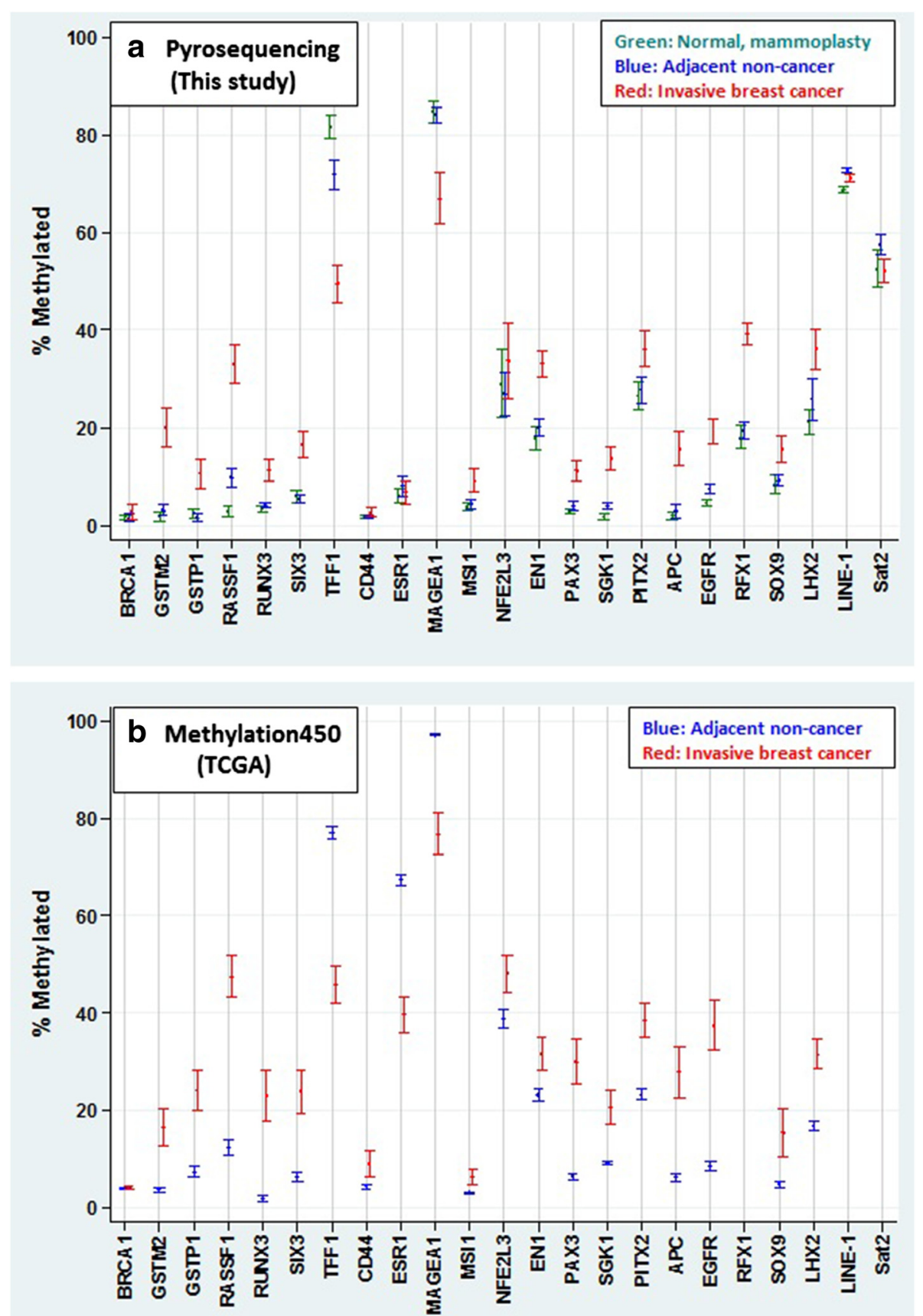

Fig. 2 Mean percent methylation and $95 \%$ error bars by gene and tissue type for the DNA regions listed in Table 1. a DNA methylation analysis of samples from the Breast Cancer Care in Chicago study (2005-2008) as determined by our bisulfite pyrosequencing. Control samples (reduction mammoplasty) from unaffected women are represented by green bars, cancer-adjacent, histologically normal samples by blue bars and cancer samples by red bars. b Bioinformatic analysis of DNA methylation of breast cancer samples and paired non-cancerous adjacent samples from The Cancer Genome Atlas (TCGA). Paired non-cancerous adjacent samples are represented by blue bars and cancer samples by red bars. In both panels, promoter sequences are displayed first, followed by upstream sequences, then introns and lastly, DNA repeats

displayed greater hypomethylation for ER/PR positive tumors. NFE2L3 displayed hypermethylation for ER positive tumors and hypomethylation for ER negative tumors $(\mathrm{p}<0.05)($ Table 4$)$.
DNA hypomethylation in cancer vs. adjacent and control mammoplasty samples

We found that the promoter regions of TFF1 and $M A G E A 1$ were hypomethylated in cancer compared 
Table 4 Adjusted differences in mean \% methylation comparing adjacent (referent) to cancer tissue, overall and stratified by ER/PR status

\begin{tabular}{|c|c|c|c|c|c|c|c|c|c|c|c|c|}
\hline & \multicolumn{3}{|c|}{ All samples } & \multirow[b]{2}{*}{$P$-Value } & \multicolumn{3}{|c|}{ ER/PR Positive } & \multirow[b]{2}{*}{$P$-Value } & \multicolumn{3}{|c|}{$\underline{\text { ER/PR Negative }}$} & \multirow[b]{2}{*}{$P$-Value } \\
\hline & $\overline{N^{a}}$ & Diff. $^{\text {b }}$ & $\overline{95 \% \mathrm{Cl}^{\mathrm{C}}}$ & & $\overline{\mathrm{N}^{a}}$ & Diff. & $95 \% \mathrm{Cl}^{\mathrm{c}}$ & & $\overline{N^{a}}$ & Diff. $^{b}$ & $95 \% \mathrm{Cl}^{\mathrm{c}}$ & \\
\hline \multicolumn{13}{|c|}{ Promoter regions } \\
\hline BRCA1 & 198 & 1.7 & $(0,4)$ & NS & 136 & 1 & $(-1,4)$ & NS & 62 & 3 & $(0,8)$ & 0.09 \\
\hline$C D 44^{e}$ & 54 & 0.5 & $(0,1)$ & NS & 32 & 0 & $(-0.4,1)$ & NS & 22 & 0 & $(0,2)$ & NS \\
\hline$E S R 1^{e}$ & 54 & -1.5 & $(-3,0)$ & 0.099 & 32 & -1 & $(-4,1)$ & NS & 22 & -2 & $(-4,1)$ & NS \\
\hline GSTM2 & 212 & 16.8 & $(13,21)$ & $<0.0001$ & 146 & 10 & $(6,16)$ & $<0.0001$ & 66 & 32 & $(24,38)$ & $<0.0001$ \\
\hline GSTP1 & 227 & 8.3 & $(6,12)$ & $<0.0001$ & 159 & 9 & $(6,14)$ & $<0.0001$ & 68 & 6 & $(2,12)$ & 0.016 \\
\hline MAGEA $1^{e}$ & 54 & -14.5 & $(-22,-9)$ & $<0.0001$ & 32 & -22 & $(-30,-14)$ & $<0.0001$ & 22 & -4 & $(-12,3)$ & NS \\
\hline $\mathrm{MSI} \mathrm{1}^{\mathrm{e}}$ & 54 & 4.7 & $(2,8)$ & 0.005 & 32 & 4 & $(1,10)$ & 0.057 & 22 & 5 & $(1,9)$ & 0.01 \\
\hline NFE2L3 ${ }^{e}$ & 54 & 5.6 & $(-4,16)$ & NS & 32 & 19 & $(9,31)$ & 0.001 & 22 & -15 & $(-26,-4)$ & 0.01 \\
\hline RASSF1A & 234 & 23.5 & $(19,28)$ & $<0.0001$ & 160 & 26 & $(21,31)$ & $<0.0001$ & 74 & 18 & $(12,25)$ & $<0.0001$ \\
\hline RUNX3 & 227 & 6.6 & $(4,9)$ & $<0.0001$ & 156 & 9 & $(6,11)$ & $<0.0001$ & 71 & 2 & $(-1,7)$ & NS \\
\hline SIX3 & 221 & 10.9 & $(9,14)$ & $<0.0001$ & 151 & 10 & $(7,14)$ & $<0.0001$ & 70 & 13 & $(8,19)$ & $<0.0001$ \\
\hline TFF1 & 230 & -21.6 & $(-26,-17)$ & $<0.0001$ & 159 & -25 & $(-30,-19)$ & $<0.0001$ & 71 & -14 & $(-23,-5)$ & 0.002 \\
\hline \multicolumn{13}{|c|}{ Upstream of promoter } \\
\hline EN1 & 230 & 13.1 & $(10,17)$ & $<0.0001$ & 158 & 12 & $(8,16)$ & $<0.0001$ & 72 & 16 & $(9,24)$ & $<0.0001$ \\
\hline PAX3 & 230 & 7.3 & $(5,10)$ & $<0.0001$ & 159 & 6 & $(4,9)$ & $<0.0001$ & 71 & 10 & $(6,15)$ & $<0.0001$ \\
\hline $\operatorname{PITX} 2^{\mathrm{e}}$ & 54 & 7.8 & $(4,11)$ & $<0.0001$ & 32 & 7 & $(3,10)$ & $<0.0001$ & 22 & 10 & $(1,16)$ & 0.026 \\
\hline SGK1 & 233 & 9.8 & $(8,12)$ & $<0.0001$ & 160 & 9 & $(7,12)$ & $<0.0001$ & 73 & 11 & $(7,16)$ & $<0.0001$ \\
\hline \multicolumn{13}{|l|}{ Introns } \\
\hline $\mathrm{APC}$ & 221 & 12.3 & $(9,16)$ & $<0.0001$ & 153 & 12 & $(8,16)$ & $<0.0001$ & 68 & 15 & $(9,22)$ & $<0.0001$ \\
\hline EGFR & 235 & 12 & $(9,15)$ & $<0.0001$ & 161 & 15 & $(11,18)$ & $<0.0001$ & 74 & 6 & $(2,11)$ & 0.009 \\
\hline $\mathrm{LHX} 2^{\mathrm{e}}$ & 54 & 8.1 & $(2,15)$ & 0.017 & 32 & 8 & $(3,13)$ & 0.006 & 22 & 9 & $(-5,22)$ & NS \\
\hline RFX1 & 235 & 19.8 & $(17,23)$ & $<0.0001$ & 161 & 20 & $(16,23)$ & $<0.0001$ & 74 & 21 & $(16,26)$ & $<0.0001$ \\
\hline SOX9 & 231 & 6.2 & $(3,9)$ & $<0.0001$ & 158 & 6 & $(3,10)$ & $<0.0001$ & 73 & 6 & $(1,13)$ & 0.031 \\
\hline \multicolumn{13}{|l|}{ DNA Repeats } \\
\hline LINE-1 & 238 & -1.5 & $(-2,-1)$ & $<0.0001$ & 162 & -2 & $(-3,-1)$ & $<0.0001$ & 76 & -1 & $(-3,0)$ & 0.074 \\
\hline Sat2 & 237 & -5.4 & $(-9,-2)$ & 0.001 & 161 & -6 & $(-10,-2)$ & 0.003 & 76 & -5 & $(-10,1)$ & 0.109 \\
\hline
\end{tabular}

${ }^{a}$ Number of samples analyzed; the small differences in numbers of samples in this table compared to Table 3 are due to missing data on ER/PR status ${ }^{b}$ Difference in mean percent methylation (cancer and adjacent) was estimated via linear regression model with generalized estimating equations to account for within-patient covariance

'Bias corrected, bootstrapped $95 \%$ confidence intervals $(\mathrm{Cl})$ were estimated via 1000 bootstrap replications to account for skewed methylation distributions ${ }^{\mathrm{d}}$ Approximate $\mathrm{p}$-value estimated from a Wald test of the normal-based bootstrapped estimate over its standard error. $P$-values $>0.1$ are suppressed 'These seven assays were not pursued beyond the pilot phase and therefore have considerably fewer cancer and adjacent tissue samples analyzed All estimates of mean percent methylation are adjusted for age, race/ethnicity, stage at diagnosis, tumor grade, and either adjusted for or stratified by ER/PR status

with adjacent samples $\left(\mathrm{p}<10^{-5}\right)$ and in cancer vs. control mammoplasty samples $\left(\mathrm{p}<10^{-4}\right.$; Tables 3 and 4$)$. MAGEA1 had high mean methylation levels in the control mammoplasty samples and adjacent samples $(>80 \%$ for both) but much lower DNA methylation levels in the cancer samples. TFF1 also had high mean methylation levels in the control mammoplasty tissue (82\%), although methylation levels were lower in adjacent tissue (72 \%), and lowest in cancer tissue (49\%). Cancerassociated hypomethylation of TFF1 and MAGEA1 was also observed by Illumina HumanMethylation 450 analysis of DNA methylation in the TCGA database for breast cancer and paired normal samples (Fig. 2b, Panel $\mathrm{b}$ and Table 5). In addition, pyrosequencing revealed that the two studied DNA repeats, the tandem, juxtacentromeric satellite 2 (Sat2) and interspersed repeat LINE-1, displayed significant hypomethylation in cancer vs. adjacent samples (Table 3). However, the extent of hypomethylation for these highly repeated sequences was much less (5.4 and $1.6 \%$, respectively), which is not surprising given the very high copy number for these repeats. 
Table 5 Methylation comparing cancer to paired adjacent samples, and correlation of methylation in invasive breast cancer samples with gene expression

\begin{tabular}{|c|c|c|c|c|c|c|c|c|c|c|c|c|c|c|c|}
\hline \multirow[b]{3}{*}{ Gene } & \multirow{3}{*}{$\begin{array}{l}\text { This } \\
\text { study } \\
\text { Pyroseq }^{\text {a }} \\
\text { \# CpG }\end{array}$} & \multicolumn{7}{|c|}{ TCGA database, within study region $+/-100 \mathrm{bp}$} & \multicolumn{7}{|c|}{ TCGA database, within study region } \\
\hline & & \multicolumn{5}{|c|}{ Illum. 450 k: Mean \% methylation } & \multicolumn{2}{|c|}{$\begin{array}{l}\text { Assn. with } \\
\text { expr. }\end{array}$} & \multicolumn{5}{|c|}{ Illum. 450 k: Mean \% Methylation } & \multicolumn{2}{|c|}{$\begin{array}{l}\text { Assn. with } \\
\text { expr. }\end{array}$} \\
\hline & & $\# \mathrm{CpG}$ & $\begin{array}{l}\text { Adjacent }^{\mathrm{b}} \\
(\mathrm{N}=96)\end{array}$ & $\begin{array}{l}\text { Cancer }^{c} \\
(\mathrm{~N}=96)\end{array}$ & Diff $^{d}$ & $P$-value & $\overline{\rho^{f}}$ & $P$-value & $\overline{\# C p G}$ & $\begin{array}{l}\text { Adjacent }^{\mathrm{b}} \\
(\mathrm{N}=96)\end{array}$ & $\begin{array}{l}\text { Cancer }^{c} \\
(\mathrm{~N}=96)\end{array}$ & Diff $^{d}$ & $P$-value $e^{\mathrm{e}}$ & $\overline{\rho^{f}}$ & $P$-value \\
\hline \multicolumn{16}{|c|}{ Promoter region } \\
\hline BRCA1 & 11 & 13 & 4 & 4 & 0 & NS & -0.19 & 0.0000 & 9 & 3 & 4 & 0 & NS & -0.20 & 0.0000 \\
\hline CD44 & 8 & 5 & 4 & 9 & 5 & 0.0001 & -0.18 & 0.0000 & 1 & 6 & 10 & 5 & 0.004 & -0.18 & 0.0000 \\
\hline ESR1 & 5 & 2 & 67 & 40 & -28 & 0.0000 & -0.52 & 0.0000 & 2 & 67 & 40 & -28 & 0.0000 & -0.52 & 0.0000 \\
\hline GSTM2 & 8 & 3 & 4 & 16 & 13 & 0.0000 & -0.13 & 0.0003 & 1 & 2 & 2 & -1 & 0.0000 & -0.13 & 0.0002 \\
\hline GSTP1 & 4 & 2 & 7 & 24 & 17 & 0.0000 & -0.43 & 0.0000 & 0 & - & - & & - & - & - \\
\hline MAGEA1 & 6 & 2 & 97 & 77 & -21 & 0.0000 & -0.23 & 0.0000 & 2 & 97 & 77 & -20 & 0.0000 & -0.23 & 0.0000 \\
\hline MSI1 & 5 & 2 & 3 & 6 & 3 & 0.0000 & -0.20 & 0.0000 & 0 & - & - & & - & - & - \\
\hline NFE2L3 & 14 & 1 & 39 & 48 & 9 & 0.0001 & -0.55 & 0.0000 & 0 & - & - & & - & - & - \\
\hline RASSF1 & 9 & 2 & 12 & 47 & 35 & 0.0000 & -0.18 & 0.0000 & 1 & 9 & 49 & 41 & 0.0000 & -0.16 & 0.0000 \\
\hline RUNX3 & 28 & 1 & 2 & 23 & 21 & 0.0000 & -0.28 & 0.0000 & 0 & - & - & & - & - & - \\
\hline SIX3 & 12 & 4 & 6 & 24 & 18 & 0.0000 & -0.21 & 0.0000 & 2 & 4 & 26 & 22 & 0.0000 & -0.20 & 0.0000 \\
\hline TFF1 & 5 & 4 & 77 & 46 & -31 & 0.0000 & -0.20 & 0.0000 & 1 & 74 & 47 & -27 & 0.0000 & -0.19 & 0.0000 \\
\hline \multicolumn{16}{|c|}{ Upstream of promoter } \\
\hline$\underline{\mathrm{EN1}}^{\mathrm{g}}$ & 6 & 2 & 23 & 32 & 8 & 0.0000 & 0.12 & 0.001 & 0 & - & - & & - & - & - \\
\hline PAX3 & 5 & 2 & 6 & 30 & 24 & 0.0000 & -0.12 & 0.004 & 1 & 9 & 29 & 19 & 0.0000 & -0.10 & 0.003 \\
\hline$\underline{\mathrm{PITX}}^{\mathrm{g}}$ & 10 & 2 & 23 & 38 & 15 & 0.0000 & 0.22 & 0.0000 & 0 & - & - & & - & - & - \\
\hline SGK1 & 6 & 4 & 9 & 21 & 12 & 0.0000 & -0.10 & 0.003 & 2 & 5 & 17 & 12 & 0.0000 & -0.11 & 0.003 \\
\hline \multicolumn{16}{|l|}{ Introns } \\
\hline$\underline{\mathrm{APC}}^{\mathrm{g}}$ & 4 & 11 & 6 & 28 & 22 & 0.0000 & 0.13 & 0.002 & 3 & 5 & 28 & 23 & 0.0000 & 0.12 & 0.004 \\
\hline EGFR & 4 & 1 & 9 & 37 & 29 & 0.0000 & -0.15 & 0.0000 & 1 & 9 & 37 & 29 & 0.0000 & -0.15 & 0.0000 \\
\hline$\underline{\mathrm{LHX}} 2^{\mathrm{g}}$ & 11 & 1 & 17 & 32 & 15 & 0.0000 & 0.24 & 0.0000 & 0 & - & - & & - & - & - \\
\hline RFX1 & 4 & 0 & - & - & & - & - & - & 0 & - & - & & - & - & - \\
\hline Sox9 & 4 & 1 & 5 & 15 & 11 & 0.0000 & -0.34 & 0.0000 & 0 & - & - & & - & & \\
\hline
\end{tabular}

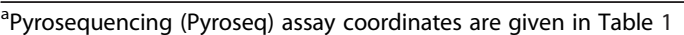

${ }^{\mathrm{b}}$ Non-cancer tissue adjacent to paired breast cancer from 96 patients in the TCGA Illumina Methylation450 database for genome-wide DNA methylation [14]

'Samples from the invasive component of the breast cancer from patients in the TCGA Methylation450 and expression (expr.; RNA-seq) databases [16, 17]

${ }^{d}$ Difference in mean \% methylation for cancer minus that for the paired adjacent tissue for the 96 patients with both in the TCGA database

${ }^{\mathrm{e}}$ From a dependent sample Wilcoxon Sign Rank test; P-values $>0.10$ are suppressed

fSpearman correlation coefficient for methylation levels vs expression levels among all the invasive breast cancer samples in the TCGA database

${ }^{9}$ The four underlined genes were the only ones that had a positive association of cancer methylation in non-promoter regions with expression levels of the

associated gene

\section{Cancer-associated aberrant methylation in adjacent tissue vs. control mammoplasty samples}

A comparison that could be made with our pyrosequencing data, that is not available in the TCGA database for breast samples, is an analysis of cancer-adjacent tissue vs. breast tissue from cancer-free individuals. Comparing methylation levels of the adjacent samples in breast cancer patients and the control mammoplasty samples revealed that RASSF1A had the largest difference in mean methylation (Table 3). Only five other sequences displayed hypermethylation or hypomethylation in adjacent vs. control mammoplasty samples at the significance level of $\mathrm{p}<0.01$ (SGK1, LINE-1, EGFR, Sat2 and TFF1; Table 3) and only the first two of these at $\mathrm{p} \leq$ 0.001 . Surprisingly, the most statistically significant difference between methylation in adjacent tissue relative 
to control mammoplasty tissue was hypermethylation of LINE-1 $\left(\mathrm{p}<10^{-9}\right)$ as contrasted with the hypomethylation of this repeat in cancer vs. adjacent samples $\left(\mathrm{p}=10^{-4}\right)$. However, the magnitude of the expected [45] hypomethylation of LINE-1 repeats in cancer vs. adjacent tissue was small (-1.6 percentage points) and the magnitude of observed hypermethylation was modest $(+4.1$ percentage points). Mammoplasty control samples came from women who were younger (mean of $33 \mathrm{y}$, range 16-68) than the patients from whom the breast cancer samples originated (mean of $56 \mathrm{y}$, range 25-77), as would be expected given the availability of such samples. In addition, there are some differences in the cellular composition of breast tissue dependent upon whether it was derived from obese women, the likely source of most mammoplasty samples [46]. Therefore, the small differences in methylation, as seen for LINE-1, need to be interpreted with caution.

\section{Correlations between cancer-associated changes in DNA methylation and gene expression}

An analysis of the Illumina HumanMethylation450 DNA methylation database for invasive breast cancers and the RNA-seq expression database for the same cancers in the TCGA collection [14] demonstrated that the methylation status of most of the studied regions was significantly associated with altered expression of the corresponding gene (Table 5). For this analysis, we focused on either the same small region studied by pyrosequencing in this study or that region extended by $100 \mathrm{bp}$ on either side (Table 5). All the promoter regions for which we demonstrated cancer-linked hypermethylation by pyrosequencing (BRCA1, CD44, GSTM2, GSTP1, MSI1, NFE2L3, RASSF1, RUNX3 and SIX3) exhibited an inverse correlation with expression among the cancers. Therefore, as expected [47], more promoter methylation was associated with lower expression levels. The two promoter regions displaying cancer hypomethylation (TFF1 and MAGEA1) also displayed an inverse correlation between methylation among cancers and expression indicating that cancerlinked losses in promoter methylation were associated with increased (and abnormal) expression. Importantly, the only regions that displayed a positive correlation between methylation and expression among the breast cancers in the TCGA database were four far-upstream or intragenic regions for the genes EN1, PITX2, APC and $L H X 2$.

Insights into DNA hypermethylation positively associated with gene expression from the ENCODE database

We compared DNA methylation from ENCODE RRBS profiles of normal breast epithelial cells (HMEC) and several breast cancer cell lines, MCF-7 and T-47D (ENCODE/RRBS/HudsonAlpha Institute; $[18,19]$ ). In addition, profiling of all mappable CpG sites in HMEC and the breast cancer cell line HCC1954 was available $[15,18]$. As expected, differences in DNA methylation between promoter regions that we examined by pyrosequencing mostly mimicked the hypermethylation or hypomethylation observed in cancer vs. adjacent tissue or control mammoplasty tissue analyses by pyrosequencing (Additional file 1: Table S1).

Next we used ENCODE data to analyze transcriptome profiles available for HMEC, many other normal cell cultures and MCF-7 in the ENCODE database (ENCODE/ RNA-seq/Cold Spring Harbor Lab) to elucidate the positive association shown in Table 5 between cancer DNA hypermethylation and gene expression for the pyrosequenced regions in EN1, LHX2, PITX2 and APC. With respect to $E N 1$, methylation of its far-upstream region was positively associated with expression in a comparison of normal cell cultures. Normal myoblast and myotube cultures, which strongly and preferentially express EN1 were significantly hypermethylated in this farupstream region when compared with other studied cell cultures and tissues [48] including HMEC and MCF-7 cells (Fig. 1c and d). Unlike myoblasts and myotubes, the MCF-7 breast cancer cell line was hypermethylated not only in this region but throughout the body of the EN1 gene, which may explain why MCF-7 cells did not express $E N 1$ while myoblasts and myotubes did. Similar to the studied EN1 far-upstream region, intron 3 of LHX2 and intron 1 of PITX2, exhibited muscle lineage hypermethylation directly associated with highly specific expression in myoblasts (data not shown, [18]). In contrast, $A P C$ is broadly expressed among diverse cell types.

Histone modifications and gene expression from ENCODE We also examined the pyrosequenced regions in ENCODE histone modification profiles, which were available for HMEC but not for MCF-7 (ENCODE/Histone Modifications by ChIP-seq/Broad Institute). As expected, promoter hypermethylation in cancer was usually in regions displaying active promoter-type histone modifications in HMEC (Additional file 1: Table S1). These histone modification profiles distinguish between chromatin regions that are predicted to be active promoters (histone H3 lysine-4 trimethylation, H3K4me3, and H3K27 acetylation, H3K27ac), silenced regions (H3K27me3), active enhancers (H3K4me1 and H3K27ac), and poised promoters or enhancers (H3K4 methylation sometimes with H3K27me3 but without H3K27ac)[49]. The histone methylation profiles (Additional file 1: Table S2) also indicate that two of the studied regions far downstream of EGFR (1.35 kb downstream of the TSS in intron 1) and SOX9 (2 kb downstream of TSS, in intron 2) have the chromatin modifications typical of active promoters in HMEC cultures, in which these genes are expressed. 
Histone modification profiles for HMEC cultures were also very informative for the four intragenic or farupstream regions that displayed breast cancer-associated DNA hypermethylation as well as a positive association between DNA methylation and expression among TCGA breast cancers (Additional file 1: Table S2). In HMEC cultures, the examined EN1, PITX2 and LHX2 chromatin regions all exhibited enrichment in H3K27me3. This histone mark is often, but not always, associated with repression and frequently found in DNA regions in normal cells (especially stem cells) that become hypermethylated during carcinogenesis [50]. The pyrosequenced region in $A P C$, unlike the above three gene regions, exhibited the histone marks of an active promoter (H3K4me3 and H3K27ac) in HMEC. However, although this region is $30 \mathrm{~kb}$ downstream of the APC TSS defined by the isoform NM_001127511, it overlaps an alternative promoter associated with isoform NM_000038. Both isoforms encode the APC protein, although their promoters are separated by $30 \mathrm{~kb}$, and both are functionally important [51]. HMEC cultures express both isoforms abundantly, as indicated by histone modification and RNA profiling in ENCODE databases (Additional file 1: Table S2). However, TCGA methylation profiles showed that only the downstream alternative promoter region becomes hypermethylated in breast cancers. The average percent methylation at the upstream and downstream promoters in invasive breast cancer in the TCGA database were 10 and 28, respectively, while those for paired normal tissue were 11 and 6 .

\section{Discussion}

Using a candidate gene approach on a large, ethnically diverse set of subjects, we compared not only invasive breast cancer and adjacent histologically normal tissue (as in the TCGA Illumina HumanMethylation450 database [14]), but also control samples of reductive mammoplasty tissue from non-cancer patients using a quantitative, gold-standard method for DNA methylation analysis (bisulfite/pyrosequencing) amenable to archival FFPE samples. Our pyrosequencing analysis of DNA methylation involved promoter DNA regions, regions far upstream of genes, intragenic regions and high-copy interspersed or tandem DNA repeats. In addition, DNA methylation, transcriptome and histone modification profiles from TCGA or ENCODE wholegenome databases were used to enhance the analysis. A limitation of our study of aberrant DNA methylation in breast cancer is that clinical samples such as ours include cell types other than breast epithelial cells. Therefore, the methylation levels estimated in our study represent an average across many cell types. Nonetheless, the similarities between hyper- or hypomethylation determined in our bioinformatic comparisons of DNA methylation in cancer-derived and normal mammary epithelial cell cultures (Additional file 1: Tables S1 and S2) and aberrant DNA methylation from our pyrosequencing study of maligant and non-cancerous breast tissues (Table 3) argue for our analysis indicating DNA changes, at least in part, in the epithelial cell populations in cancers vs. non-cancerous breast samples.

Besides confirming that a wide variety of DNA sequences display hyper- or hypomethylation in a large, diverse collection of invasive breast cancers vs. adjacent tissue, we demonstrated significant hyper- or hypomethylation in six of the 16 DNA regions examined in both 15 - 18 reduction mammoplasty samples and more than 100 histologically normal tissue samples adjacent to the breast cancers. These six DNA sequences were in promoter regions (RASSF1 and TFF1), an intron (EGFR), a far-upstream (SGK1) gene regions or DNA repeats (LINE-1 and Sat2). If control mammoplasty samples are mimicking the epigenetics of normal breast tissue, then our results suggest a field effect that could include changes which predispose to carcinogenesis [12]. The adjacent tissue samples used in our comparison had been carefully evaluated morphologically and histologically for no evidence of malignancy. In addition, the lack of evidence for a field effect for most of the studied DNA regions, including for regions with frequent hypermethylation in the cancer tissue (e.g., RFX1 and EN1), is consistent with a field effect rather than contamination of adjacent samples with tumor tissue.

Field effects for DNA methylation changes in RASSF1, EGFR and TFF1 might be important in influencing preneoplastic changes in gene expression relevant to tumor development. RASSF1 is a tumor suppressor gene that regulates apoptotic and cell cycle checkpoints [52]. RASSF1 hypermethylation has been detected in carcinoma in situ and invasive breast cancer and is inversely correlated with RNA and protein expression levels [24, 53, 54] and overall survival [55]. Like overexpression of HER-2 protein, overexpression of EGFR protein, another member of the epidermal growth factor/tyrosine kinase family, is related to multiple drug resistance and decreased patient survival $[56,57]$. We demonstrated significant hypermethylation of EGFR at part of the extended promoter-like chromatin region (see below) in intron 1 by comparing cancers with adjacent tissue. Hypermethylation in this region was also seen in the comparison of histologically normal, cancer-adjacent tissue and control mammoplasty tissue. Given the protooncogene status assigned to $E G F R$, it is not yet clear what role hypermethylation of EGFR might play in breast cancer progression.

Expression of TFF1, a gene encoding a small secretory peptide implicated in preserving mucosa in the intestinal track, is associated with promoter hypomethylation in cultured cells and in breast cancers $[29,58]$. We found 
hypomethylation of the promoter of this estrogeninducible gene in both cancer vs. adjacent tissue and in adjacent vs. control mammoplasty tissue. Expression of TFF1 in breast cancer may be associated with a poor outcome based upon breast cancer cell lines and a mouse model [59]. However, a recent study of breast cancer patients found that TFF1 expression was greater for ER/PR positive breast cancers, which generally have a better prognosis than ER/PR negative breast cancers [60]. Similarly, we found that ER/PR positive tumors showed greater hypomethylation compared with ER/PR negative tumors.

One surprising result from our analysis was that the extended promoter region of $B R C A 1$ did not show significant hypermethylation in breast cancer relative to adjacent tissue or control mammoplasty tissue despite the fact that we chose a promoter region for analysis similar to or overlapping those employed in other studies, many of which did find BRCA1 hypermethylation in breast cancer $[28,31,61-64]$. The first three of these studies used end-point methylation-specific PCR, which is extremely sensitive for detection of any DNA methylation but is not quantitative, and these studies reported only the percentages of samples that were called as methylated. We found very low average levels of methylation in the $B R C A 1$ promoter region in all samples (1.4, 1.6 and $3 \%$ for control mammoplasty, adjacent and cancer samples, respectively) including a few outliers with considerable methylation. In a study using MALDI-TOF mass array analysis of $48 \mathrm{FFPE}$ samples, only five of the 17 tested CpG sites displayed hypermethylation in breast cancer vs. matching control tissue, and the extent of hypermethylation at these five sites was surprising high (averages of about $90 \%$ for cancers vs. about $10 \%$ for controls) [63]. However, as in our study, MALDI-TOF [65] and methylation-specific multiplex ligation assays [64] by two other groups, each using flash-frozen breast cancers and matching control tissue, revealed only low percentages of cancers with greater BRCA1 methylation compared with controls. Moreover, in their studies and ours there was much more frequent cancer hypermethylation at many other tested promoter regions. Similarly, bioinformatic analysis of methylation levels in the HumanMethylation450 TCGA database revealed insignificant differences between breast cancer and adjacent tissue for the $B R C A 1$ promoter region that we examined (Table 5).

Our results from pyrosequencing that intronic sequences far downstream of the canonical promoter region (EGFR, LHX2, SOX9 and RFX1) and intergenic sequences upstream of the promoter (PAX3 and EN1) were significantly hypermethylated in breast cancer may be related to new understandings of the transcriptionregulatory roles played by DNA methylation in intragenic and distant intergenic regions $[2,66]$. For example, sequences considerably downstream of the TSS may be part of the functional promoter or of transcriptionelongation regulatory elements such that local methylation could alter gene expression levels. This may be the case for the pyrosequenced regions of EGFR (1.35 kb downstream of the TSS in intron 1) and SOX9 (2 kb downstream of TSS, in intron 2) far downstream of the TSS. These two regions displayed hypermethylation in cancer. In normal HMEC, where these two genes are actively transcribed, ENCODE histone modification profiling (Additional file 1: Table S2) indicates that the studied regions overlap large chromatin segments with histone modifications typical of active promoters starting in the canonical promoter region and continuing into the 5 ' intragenic region [13].

The importance of not restricting analysis of cancerlinked aberrant DNA methylation to standard promoter regions is also apparent from recent studies providing evidence that DNA hypermethylation is implicated in alternative promoter usage; regulating splicing of RNA; and, in certain intragenic regions, in upregulating expression [2, 66]. Indeed, examples of the latter were seen in our bioinformatic analyses of databases for DNA methylation and expression in breast cancers (TCGA) and in cultured cells (ENCODE). For example, we found that DNA hypermethylation at $A P C$ was positively associated with increased expression among breast cancers (TCGA database). While the examined APC region is $30 \mathrm{~kb}$ downstream of the TSS in intron 1 of one $A P C$ isoform expressed in HMEC, it is also in the promoter region of another protein-coding isoform of the gene transcribed in HMEC. Therefore, the cancer-associated hypermethylation of this $A P C$ intron/promoter region might help regulate levels of alternate promoter usage for this gene.

The other three breast cancer-associated DNA hypermethylated regions which displayed significantly more expression in breast cancers with higher levels of DNA methylation are $5.6 \mathrm{~kb}$ upstream of $E N 1,7 \mathrm{~kb}$ upstream of PITX2 or $4 \mathrm{~kb}$ downstream of the TSS of LHX2. These genes code for homeobox-containing transcription factors important in development. The location of these regions and their association with normally repressive H3K27me3 in HMEC cultures (Additional file 1: Table S2) suggest that the positive correlation of DNA methylation at these regions with transcription may be due to their playing a role in controlling the borders of active promoter regions and counteracting the spread of H3K27me3-repressive chromatin into the core promoter [67].

\section{Conclusions}

We identified frequent DNA methylation changes in invasive breast cancer at a variety of genome locations and found evidence for an extensive field effect in breast 
cancer. Empirical and bioinformatic analyses of these gene regions provide further examples of the power of combining a candidate gene approach and bioinformatics using publicly available databases to better understand the importance of cancer epigenetic changes.

\section{Additional file}

Additional file 1: Table S1. "Promoter test region genes" and "Table S2. Non-promoter test region genes". Two tables containing sources of and interpretation of DNA methylation, histone modification and expression data for the selected genetic regions in the pyrosequencing study. Table S1. describes regions found in gene promoter locations. Table S2. describes regions found in intragenic or far-upstream regions to genes. (DOCX $54 \mathrm{~kb})$

\section{Abbreviations}

TCGA: The Cancer Genome Atlas; ENCODE: Encyclopedia of DNA Elements; FFPE: Formalin-fixed, paraffin-embedded; RLUs: Relative light units; S/N: Signal to noise; RRBS: Reduced representation bisulfite sequencing adjacent tissue, histologically normal tissue adjacent to the cancer; HMEC: Human mammary epithelial cells; 5mC: 5-Methylcytosine; ER: Estrogen receptor; PR: Progesterone receptor; HER2: Human epidermal growth factor receptor-2; SD: Standard deviation; TSS: Transcription start site.

\section{Competing interests}

The authors declare that they have no competing interests.

\section{Authors' contributions}

GHR and ME drafted the manuscript and analyzed and interpreted the data, and JKK helped edit the manuscript. JKK, UAA, and DT collected samples. JKK and ME selected genomic regions to be investigated. MP and LY performed pyrosequencing. $V M, A M, A A B$ and ELW performed pathological examination of the samples. All authors edited and reviewed the manuscript.

\section{Acknowledgments}

Financial support provided by a grant from NIH (2P50CA106743-06) to the University of Illinois at Chicago (GHR) and a Louisiana Cancer Research Center grant (ME). We would like to thank the Illinios Department of Public Health, Illinois State Cancer Registry for the case-finding for the parent study, and the patients who participated in the Breast Cancer Care in Chicago study. We would also like to thank the specimen donors of TCGA, Johns Hopkins University and University of Southern California for the DNA methylation data (Infinium HumanMethylation450) and the University of North Carolina for the gene expression data (lllumina HighSeq 2000 Total RNA Sequencing Version 2).

\section{Author details}

'Division of Epidemiology and Biostatistics, University of Illinois-Chicago, School of Public Health, M/C 923, Chicago, IL 60612, USA. EpigenDx, Inc., Hopkinton, MA, USA. ${ }^{3}$ Department of Pathology, University of Illinois-Chicago, Chicago, IL, USA. ${ }^{4}$ Department of Biopharmaceutical Sciences, University of Illinois-Chicago, Chicago, IL, USA. ${ }^{5}$ Human Genetics Program, Tulane Cancer Center, and Center for Bioinformatics and Genomics, Tulane University Health Sciences Center, 1430 Tulane Ave., New Orleans, LA 70112, USA.

\section{Received: 18 August 2015 Accepted: 9 October 2015}

Published online: 29 October 2015

\section{References}

1. Heichman KA, Warren JD. DNA methylation biomarkers and their utility for solid cancer diagnostics. Clin Chem Lab Med. 2012;50(10):1707-21.

2. Ehrlich M, Lacey M. DNA methylation and differentiation: silencing, upregulation and modulation of gene expression. Epigenomics. 2013:5(5):553-68.

3. Gama-Sosa MA, Slagel VA, Trewyn RW, Oxenhandler R, Kuo KC, Gehrke CW, et al. The 5-methylcytosine content of DNA from human tumors. Nucleic Acids Res. 1983;11(19):6883-94.
4. Feinberg AP, Vogelstein B. Hypomethylation distinguishes genes of some human cancers from their normal counterparts. Nature. 1983;301(5895):89-92.

5. Varley KE, Gertz J, Bowling KM, Parker SL, Reddy TE, Pauli-Behn F, et al. Dynamic DNA methylation across diverse human cell lines and tissues. Gen Res. 2013;23(3):555-67.

6. Berman BP, Weisenberger DJ, Aman JF, Hinoue T, Ramjan Z, Liu Y, et al. Regions of focal DNA hypermethylation and long-range hypomethylation in colorectal cancer coincide with nuclear lamina-associated domains. Nat Genet. 2012;44(1):40-6.

7. Costello JF, Frühwald MC, Smiraglia DJ, Rush LJ, Robertson GP, Gao X, et al, Aberrant CpG-island methylation has non-random and tumour-type-specific patterns. Nat Genet. 2000;24(2):132-8.

8. Ehrlich M, Jiang G, Fiala E, Dome JS, Yu MC, Long Tl, et al. Hypomethylation and hypermethylation of DNA in Wilms tumors. Oncogene. 2002;21(43):6694-702.

9. Esteller M, Corn PG, Baylin SB, Herman JG. A gene hypermethylation profile of human cancer. Cancer Res. 2001;61(8):3225-9.

10. Ehrlich M. DNA methylation in cancer: too much, but also too little. Oncogene. 2002;21(35):5400-13.

11. Lewis CM, Cler LR, Bu DW, Zöchbauer-Müller S, Milchgrub S, Naftalis EZ, et al. Promoter hypermethylation in benign breast epithelium in relation to predicted breast cancer risk. Clin Cancer Res. 2005;11(1):166-72.

12. Yan PS, Venkataramu C, Ibrahim A, Liu JC, Shen RZ, Diaz NM, et al. Mapping geographic zones of cancer risk with epigenetic biomarkers in normal breast tissue. Clin Cancer Res. 2006;12(22):6626-36.

13. UCSC Genome Browser [https://genome.ucsc.edu] Access date 2015.

14. TCGA Research Network [http://cancergenome.nih.gov/] Access date 2015.

15. Hon GC, Hawkins RD, Caballero OL, Lo C, Lister R, Pelizzola M, et al. Global DNA hypomethylation coupled to repressive chromatin domain formation and gene silencing in breast cancer. Genome Res. 2012;22(2):246-58.

16. Gao J, Aksoy BA, Dogrusoz U, Dresdner G, Gross B, Sumer SO, et al. Integrative analysis of complex cancer genomics and clinical profiles using the cBioPortal. Sci Signal. 2013;6(269):11.

17. Cerami E, Gao J, Dogrusoz U, Gross BE, Sumer SO, Aksoy BA, et al. The cBio cancer genomics portal: an open platform for exploring multidimensional cancer genomics data. Cancer Discov. 2012;2(5):401-4.

18. Kent WJ, Sugnet CW, Furey TS, Roskin KM, Pringle TH, Zahler AM, et al. The human genome browser at UCSC. Genome Res. 2002;12(6):996-1006.

19. Myers RM, Stamatoyannopoulos J, Snyder M, Dunham I, Hardison RC, Bernstein BE, et al. A user's guide to the encyclopedia of DNA elements (ENCODE). PLoS Biol. 2011;9(4):e1001046.

20. Montero AJ, Díaz-Montero CM, Mao L, Youssef EM, Estecio M, Shen L, et al. Epigenetic inactivation of EGFR by CPG island hypermethylation in cancer. Cancer Biol Ther. 2006;5(11):1494-501.

21. Lee JS. GSTP1 promoter hypermethylation is an early event in breast carcinogenesis. Virchows Arch. 2007;450(6):637-42.

22. Kim MS, Lee J, Oh T, Moon Y, Chang E, Seo KS, et al. Genome-wide identification of OTP gene as a novel methylation marker of breast cancer. Oncol Rep. 2012;27(5):1681-8.

23. Lian ZQ, Wang Q, Li WP, Zhang AQ, Wu L. Screening of significantly hypermethylated genes in breast cancer using microarray-based methylated-CpG island recovery assay and identification of their expression levels. Int J Oncol. 2012;41(2):629-38.

24. Pasquali L, Bedeir A, Ringquist S, Styche A, Bhargava R, Trucco G. Quantification of $\mathrm{CpG}$ island methylation in progressive breast lesions from normal to invasive carcinoma. Cancer Lett. 2007;257(1):136-44.

25. Subramaniam MM, Chan JY, Soong R, Ito K, Ito Y, Yeoh KG, et al. RUNX3 inactivation by frequent promoter hypermethylation and protein mislocalization constitute an early event in breast cancer progression. Breast Cancer Res Treat. 2009;113(1):113-21.

26. Jin Z, Tamura G, Tsuchiya T, Sakata K, Kashiwaba M, Osakabe M, et al. Adenomatous polyposis coli (APC) gene promoter hypermethylation in primary breast cancers. Br J Cancer. 2001;85(1):69-73.

27. Dobrovic A, Simpfendorfer D. Methylation of the BRCA1 gene in sporadic breast cancer. Cancer Res. 1997:57(16):3347-50

28. Esteller M, Silva JM, Dominguez G, Bonilla F, Matias-Guiu X, Lerma E, et al. Promoter hypermethylation and BRCA1 inactivation in sporadic breast and ovarian tumors. J Natl Cancer Inst. 2000;92(7):564-9.

29. Martin V, Ribieras S, Song-Wang XG, Lasne Y, Frappart L, Rio MC, et al. Involvement of DNA methylation in the control of the expression of an estrogen-induced breast-cancer-associated protein (pS2) in human breast cancers. J Cell Biochem. 1997;65(1):95-106. 
30. Jackson K, Yu MC, Arakawa K, Fiala E, Youn B, Fiegl H, et al. DNA hypomethylation is prevalent even in low-grade breast cancers. Cancer Biol Ther. 2004;3(12):1225-31.

31. Cho YH, Yazici H, Wu HC, Terry MB, Gonzalez K, Qu M, et al. Aberrant promoter hypermethylation and genomic hypomethylation in tumor, adjacent normal tissues and blood from breast cancer patients. Anticancer Res. 2010;30(7):2489-96.

32. Beltran AS, Graves LM, Blancafort P. Novel role of Engrailed 1 as a prosurvival transcription factor in basal-like breast cancer and engineering of interference peptides block its oncogenic function. Oncogene. 2013;33:4767-77.

33. Slater AA, Alokail M, Gentle D, Yao M, Kovacs G, Maher ER, et al. DNA methylation profiling distinguishes histological subtypes of renal cell carcinoma. Epigenetics. 2013;8(3):252-67.

34. Ohashi $Y$, Ueda M, Kawase T, Kawakami Y, Toda M. Identification of an epigenetically silenced gene, RFX1, in human glioma cells using restriction landmark genomic scanning. Oncogene. 2004;23(47):7772-9.

35. Zheng S, Houseman EA, Morrison Z, Wrensch MR, Patoka JS, Ramos C, et al. DNA hypermethylation profiles associated with glioma subtypes and EZH2 and IGFBP2 mRNA expression. Neuro Oncol. 2011;13(3):280-9.

36. Kanafi M, Majumdar D, Bhonde R, Gupta P, Datta I. Midbrain cues dictate differentiation of human dental pulp stem cells towards functional dopaminergic neurons. J Cell Physiol. 2014;229(10):1369-77.

37. Hoque MO, Prencipe M, Poeta ML, Barbano R, Valori VM, Copetti M, et al. Changes in $\mathrm{CpG}$ islands promoter methylation patterns during ductal breast carcinoma progression. Cancer Epidemiol Biomarkers Prev. 2009;18(10):2694-700.

38. Christensen BC, Kelsey KT, Zheng S, Houseman EA, Marsit CJ, Wrensch MR, et al. Breast cancer DNA methylation profiles are associated with tumor size and alcohol and folate intake. PLoS Genet. 2010;6(7):e1001043.

39. Kagara N, Huynh KT, Kuo C, Okano H, Sim MS, Elashoff D, et al. Epigenetic regulation of cancer stem cell genes in triple-negative breast cancer. Am J Pathol. 2012;181(1):257-67.

40. Otte M, Zafrakas M, Riethdorf L, Pichlmeier $U$, Loning $T$, Janicke $F$, et al. MAGE-A gene expression pattern in primary breast cancer. Cancer Res. 2001;61(18):6682-7.

41. Simpson AJ, Caballero OL, Jungbluth A, Chen YT, Old LJ. Cancer/testis antigens, gametogenesis and cancer. Nat Rev Cancer. 2005:5(8):615-25.

42. Warnecke PM, Stirzaker C, Song J, Grunau C, Melki JR, Clark SJ. Identification and resolution of artifacts in bisulfite sequencing. Methods. 2002;27(2):101-7.

43. Tost J, Gut IG. DNA methylation analysis by pyrosequencing. Nat Protoc. 2007;2(9):2265-75

44. von Ahlfen S, Missel A, Bendrat K, Schlumpberger M. Determinants of RNA quality from FFPE samples. PLoS One. 2007;2(12):e1261.

45. Schulz WA, Steinhoff C, Florl AR. Methylation of endogenous human retroelements in health and disease. Curr Top Microbiol Immunol. 2006;310:211-50.

46. Sun X, Casbas-Hernandez P, Bigelow C, Makowski L, Joseph Jerry D, Smith Schneider $\mathrm{S}$, et al. Normal breast tissue of obese women is enriched for macrophage markers and macrophage-associated gene expression. Breast Cancer Res Treat. 2012;131(3):1003-12.

47. Jones PA. The DNA methylation paradox. Trends Genet. 1999;15(1):34-7.

48. Tsumagari K, Baribault C, Terragni J, Varley KE, Gertz J, Pradhan S, et al. Early de novo DNA methylation and prolonged demethylation in the muscle lineage. Epigenetics. 2013;8(3):317-32.

49. Ernst J, Kheradpour P, Mikkelsen TS, Shoresh N, Ward LD, Epstein CB, et al. Mapping and analysis of chromatin state dynamics in nine human cell types. Nature. 2011;473(7345):43-9.

50. Easwaran H, Johnstone SE, Van Neste L, Ohm J, Mosbruger T, Wang Q, et al. A DNA hypermethylation module for the stem/progenitor cell signature of cancer. Genome Res. 2012;22(5):837-49.

51. Rohlin A, Engwall Y, Fritzell K, Göransson K, Bergsten A, Einbeigi Z, et al. Inactivation of promoter $1 \mathrm{~B}$ of APC causes partial gene silencing: evidence for a significant role of the promoter in regulation and causative of familial adenomatous polyposis. Oncogene. 2011;30(50):4977-89.

52. Donninger $H$, Vos MD, Clark GJ. The RASSF1A tumor suppressor. J Cell Sci. 2007;120(Pt 18):3163-72.

53. Alvarez C, Tapia T, Cornejo V, Fernandez W, Muñoz A, Camus M, et al. Silencing of tumor suppressor genes RASSF1A, SLIT2, and WIF1 by promoter hypermethylation in hereditary breast cancer. Mol Carcinog. 2013;52(6):475-87.
54. Dammann R, Yang G, Pfeifer GP. Hypermethylation of the cpG island of Ras association domain family 1A (RASSF1A), a putative tumor suppressor gene from the 3p21.3 locus, occurs in a large percentage of human breast cancers. Cancer Res. 2001;61(7):3105-9.

55. Xu J, Shetty PB, Feng W, Chenault C, Bast RC, Issa JP, et al. Methylation of HIN-1, RASSF1A, RIL and CDH13 in breast cancer is associated with clinical characteristics, but only RASSF1A methylation is associated with outcome. BMC Cancer. 2012;12:243.

56. Kreutzer JN, Salvador A, Diana P, Cirrincione G, Vedaldi D, Litchfield DW, et al. 2-Triazenoazaindoles: a novel class of triazenes inducing transcriptional down-regulation of EGFR and HER-2 in human pancreatic cancer cells. Int J Oncol. 2012;40(4):914-22.

57. Davis NM, Sokolosky M, Stadelman K, Abrams SL, Libra M, Candido S, et al. Deregulation of the EGFR/PI3K/PTEN/Akt/mTORC1 pathway in breast cancer: possibilities for therapeutic intervention. Oncotarget. 2014;5(13):4603-50.

58. Fleischer T, Edvardsen H, Solvang HK, Daviaud C, Naume B, Børresen-Dale $\mathrm{AL}$, et al. Integrated analysis of high-resolution DNA methylation profiles, gene expression, germline genotypes and clinical end points in breast cancer patients. Int J Cancer. 2014;134(11):2615-25.

59. Buache E, Etique N, Alpy F, Stoll I, Muckensturm M, Reina-San-Martin B, et al. Deficiency in trefoil factor 1 (TFF1) increases tumorigenicity of human breast cancer cells and mammary tumor development in TFF1-knockout mice. Oncogene. 2011;30(29):3261-73.

60. Markićević M, Džodić R, Buta M, Kanjer K, Mandušić V, NeškovićKonstantinović Z, et al. Trefoil factor 1 in early breast carcinoma: a potential indicator of clinical outcome during the first 3 years of follow-up. Int J Med Sci. 2014;11(7):663-73.

61. Wei M, Grushko TA, Dignam J, Hagos F, Nanda R, Sveen L, et al. BRCA1 promoter methylation in sporadic breast cancer is associated with reduced BRCA1 copy number and chromosome 17 aneusomy. Cancer Res. 2005;65(23):10692-9.

62. Matros E, Wang ZC, Lodeiro G, Miron A, Iglehart JD, Richardson AL. BRCA1 promoter methylation in sporadic breast tumors: relationship to gene expression profiles. Breast Cancer Res Treat. 2005;91(2):179-86.

63. Radpour R, Kohler C, Haghighi MM, Fan AX, Holzgreve W, Zhong XY. Methylation profiles of 22 candidate genes in breast cancer using highthroughput MALDI-TOF mass array. Oncogene. 2009;28(33):2969-78.

64. Jung EJ, Kim IS, Lee EY, Kang JE, Lee SM, Kim DC, et al. Comparison of methylation profiling in cancerous and their corresponding normal tissues from korean patients with breast cancer. Ann Lab Med. 2013;33(6):431-40.

65. Bardowell SA, Parker J, Fan C, Crandell J, Perou CM, Swift-Scanlan T. Differential methylation relative to breast cancer subtype and matched normal tissue reveals distinct patterns. Breast Cancer Res Treat. 2013;142(2):365-80.

66. Shenker N, Flanagan JM. Intragenic DNA methylation: implications of this epigenetic mechanism for cancer research. Br J Cancer. 2012;106(2):248-53.

67. Ehrlich M, Ehrlich KC. DNA cytosine methylation and hydroxymethylation at the borders. Epigenomics. 2014;6(6):563-6.

\section{Submit your next manuscript to BioMed Central and take full advantage of:}

- Convenient online submission

- Thorough peer review

- No space constraints or color figure charges

- Immediate publication on acceptance

- Inclusion in PubMed, CAS, Scopus and Google Scholar

- Research which is freely available for redistribution 